\title{
Selective laser trabeculoplasty $v$ argon laser trabeculoplasty: a prospective randomised clinical trial
}

\author{
Karim F Damji, Kirtida C Shah, William J Rock, Harkaran S Bains, William G Hodge
}

\begin{abstract}
Aims-To compare the effectiveness of selective laser trabeculoplasty (SLT, a $532 \mathrm{~nm}$ Nd:YAG laser) with argon laser trabeculoplasty (ALT) in lowering the intraocular pressure (IOP) in patients with medically uncontrolled open angle glaucoma.
\end{abstract}

Methods-A prospective randomised clinical trial was designed. Patients were randomised to treatment with either SLT or ALT and were evaluated at 1 hour, 1 week, 1, 3, and 6 months post-laser.

Results-There were 18 eyes in each group. Baseline characteristics were similar in both groups. In the SLT group the mean IOP at baseline, 1, 3, and 6 months was 22.8 (SD 3.0), 20.1 (4.6), $19.3(6.0)$, and $17.8(4.8) \mathrm{mm} \mathrm{Hg}$, respectively. In the ALT group, the mean IOP at baseline, 1,3 , and 6 months was $22.5(3.6), 19.5$ (4.7), 19.6 (5.6), and 17.7 (3.3) $\mathrm{mm} \mathrm{Hg}$, respectively. There was a greater anterior chamber reaction, 1 hour after SLT $v$ ALT $(p<$ 0.01). Patients with previous failed ALT had a better reduction in IOP with SLT than with repeat ALT (6.8 (2.4) v 3.6 (1.8) mm Hg; $p=0.01$ ).

Conclusion-SLT appears to be equivalent to ALT in lowering IOP during the first 6 months after treatment. There is a slightly greater anterior chamber reaction 1 hour after SLT. Patients with previous failed ALT had a significantly greater drop in IOP when treated with SLT $v$ ALT. These results need to be confirmed with a larger sample size.

(Br F Ophthalmol 1999;83:718-722)

Argon laser trabeculoplasty (ALT) has become the standard method of treatment for medically uncontrolled open angle glaucoma in North America. ${ }^{12}$ It has been in use since 1979 when it was first described by Wise and Witter. $^{3}$ Argon laser $(\lambda=488-514 \mathrm{~nm})$ improves the outflow of aqueous by photocoagulation of the trabecular meshwork (TM). A number of theories have been proposed to explain this effect of ALT on aqueous outflow. The most widely accepted are the mechanical and cellular theories. According to the mechanical theory, ALT causes coagulative damage to the trabecular meshwork, which results in collagen shrinkage and subsequent scarring of the TM. This tightens the meshwork in the area of each burn and reopens the adjacent, untreated intertrabecular spaces. ${ }^{2-4}$ The cellu- lar theory proposes that in response to coagulative necrosis induced by the laser, there is migration of macrophages, which phagocytose debris and thus clear the TM.

Different types of lasers with various wavelengths are being investigated for laser trabeculoplasty. Recently, a $Q$ switched, frequency doubled Nd:YAG laser $(\lambda=532 \mathrm{~nm})$ has been described for use in trabeculoplasty ${ }^{5-7}$ (Mark A Latina, presented at AAO Annual Meeting, San Francisco, 1997). In tissue cultures, it has been demonstrated that the low power and short duration of this laser can selectively target pigmented TM cells while sparing adjacent cells and tissues from collateral thermal damage and can thus maintain the architecture of the TM. ${ }^{8}$ This procedure has thus been termed selective laser trabeculoplasty (SLT).

The objective of our study was to compare the efficacy of SLT and ALT in lowering the intraocular pressure (IOP) in patients with open angle glaucoma in a prospective randomised clinical trial.

\section{Patients and methods}

A prospective randomised clinical trial was approved by the research ethics board of Ottawa Hospital. The patients included in this trial were those referred to the glaucoma clinic at the University of Ottawa Eye Institute. Patients were included if they had open angle glaucoma (to increase the generalisability of the trial, pigmentary and pseudoexfoliation glaucoma were also included) with uncontrolled IOP $(>16 \mathrm{~mm} \mathrm{Hg}$ ) on maximal medical therapy or failed previous 180/360 degree ALT ( $\geqslant 6$ months previously), were over 18 years of age, had two sighted eyes, and were willing to participate. Patients were excluded if there was any evidence of glaucoma other than open angle glaucoma (if the TM could not be visualised 360 degrees); if an advanced visual field defect (scotoma within 10 degrees of fixation or split fixation on Humphrey visual field 24-2, full threshold program) was present in the eye being considered for treatment; if the patient had previous glaucoma surgery done (other than ALT or peripheral laser iridotomy (PI)), or required any ocular surgery within 6 months post-laser in the study eye; if there was corneal disease precluding an adequate view of the trabecular meshwork; or if the patient was on systemic steroids or had a concurrent condition warranting treatment with systemic steroids within the study period.

Baseline examinations included variables such as age, sex, history of any risk factors for glaucoma (myopia, hypertension, diabetes, 
Table 1 Baseline characteristics

\begin{tabular}{|c|c|c|}
\hline & $S L T$ & $A L T$ \\
\hline Age (SD) (years) & $69(9.3)$ & $65(10.6)$ \\
\hline \multicolumn{3}{|l|}{ Sex: } \\
\hline Male & 8 & 9 \\
\hline Female & 9 & 8 \\
\hline \multicolumn{3}{|l|}{ Diagnosis: } \\
\hline $\mathrm{POAG}^{\star}$ & 8 & 11 \\
\hline Pseudoexfoliation glaucoma & 5 & 5 \\
\hline Pigmentary glaucoma & 2 & 1 \\
\hline OAG status post PI $\dagger$ & 2 & 1 \\
\hline Aphakic glaucoma & 1 & - \\
\hline \multicolumn{3}{|l|}{ Risk factors: } \\
\hline Hypertension & 3 & 0 \\
\hline Diabetes & 1 & 1 \\
\hline Myopia & 1 & 1 \\
\hline Family history of glaucoma & 2 & 4 \\
\hline Others & 6 & 5 \\
\hline Multiple risk factors & 1 & 1 \\
\hline No risk factors & 4 & 6 \\
\hline \multicolumn{3}{|l|}{ Eye treated: } \\
\hline $\mathrm{R}$ & 11 & 8 \\
\hline $\mathrm{L}$ & 7 & 10 \\
\hline \multicolumn{3}{|l|}{ No of glaucoma medications: } \\
\hline 1 & 4 & 8 \\
\hline 2 & 7 & 5 \\
\hline 3 & 4 & 4 \\
\hline 4 & 2 & 1 \\
\hline 5 & 1 & 0 \\
\hline Failed previous ALT & 7 & 8 \\
\hline TM pigmentation (SD) & $2.5(0.9)$ & $2.4(1.0)$ \\
\hline
\end{tabular}

$\star$ POAG $=$ primary open angle glaucoma.

$+\mathrm{PI}=$ peripheral iridotomy.

race, thyroid disease, and family history of glaucoma), a history of past and present ocular medication, and history of any ocular surgeries done including any laser therapy (ALT/PI) to the study eye.

Ocular assessment included corrected visual acuity, slit lamp assessment of the anterior segment of the eye, and gonioscopy of the angle. Trabecular meshwork pigmentation was graded according to a standard scale provided by Coherent Medical (graded from 0 to $4+$ where $0=$ no pigment and $4+=$ dense homogeneous pigment). IOP was measured with a Goldmann applanation tonometer at approximately the same time of day (plus or minus 1 hour) for all follow up visits to minimise diurnal variation of IOP. Stereoscopic optic nerve examination was performed with a Volk 90D lens. On the day of laser trabeculoplasty, IOP was checked and one drop of $1 \%$ apraclonidine was instilled in the study eye. Patients were then treated with either SLT or ALT according to a blocked randomisation schedule using blocks of six. The allocation schedule was computer generated. The generator of the random allocation (WGH) in no way participated in executing the intervention and the executors (KFD, WJR) did not participate in generating the schedule in any way. The clinicians (KFD, WJR) who administered the laser were not masked as to the treatment allocation. The inferior $180^{\circ}$ of the angle was generally treated unless the patient had previous ALT to the inferior half in which case the superior $180^{\circ}$ was treated. ALT was performed using 50 applications of $50 \mu \mathrm{m}$ spot size, 0.1 second duration, and an average power ranging from 400 to $600 \mathrm{~mW}$ directed through an antireflection coated Goldmann lens to produce blanching or occasional bubble formation in the anterior TM. SLT was performed with Selecta 7000 (Q switched, frequency doubled, 532
Nd:YAG laser) using 50 non-overlapping applications, with a spot size of $400 \mu \mathrm{m}$ (centred on the TM) and pulse duration of $3 \mathrm{~ns}$. The initial energy used was $0.8 \mathrm{~mJ}$. The energy was increased or decreased until bubble formation appeared and was then decreased by $0.1 \mathrm{~mJ}$ for the remainder of the treatment. Average power during treatment ranged from 0.8 to $1.4 \mathrm{~mJ}$. A drop of $1 \%$ apraclonidine was instilled in all treated eyes post-laser. One hour post-laser IOP was checked and the anterior chamber reaction was assessed (cells and flare graded on a scale from 0 (no reaction) to +4 (very marked reaction)). ${ }^{9}$ If pressure was high, $500 \mathrm{mg}$ of acetazolamide was given to the patient and pressures were checked after an additional hour. When stable, patients were sent home on prednisolone acetate $1 \%$ to be instilled in the treated eye four times a day for 5 days. An attempt was made to keep the patient on the same glaucoma medications prescribed at the study inception for the duration of the study. The medication was changed only if the pressure worsened significantly from preoperative status, or if an adequate drop in IOP was not seen. Patients were evaluated at end of 1 week, then at approximately 1,3 , and 6 months. At all follow up examinations, the best corrected vision, anterior chamber reaction, IOP, grade of trabecular pigmentation, presence of any peripheral anterior synechiae, and cup to disc ratio were noted.

\section{STATISTICAL ANALYSIS}

The distribution of baseline characteristics was compared between the two groups for all potential confounders (age, sex, type of glaucoma, glaucoma risk factors, number of glaucoma medications, past ocular surgery, and amount of trabecular pigmentation). For continuous variables, the mean was compared using a non-paired $t$ test after checking for normality using an inverse normal plot. For binary variables, proportions were compared using the $\chi^{2}$ test. Given that no differences were found among baseline variables, we took the liberty of comparing the outcome between groups in both a univariate and multivariate manner.

For univariate analysis, we used the same tests as for the baseline characteristics. For the multivariate analysis continuous outcomes were compared using multiple linear regression controlling for the above mentioned covariates. As expected the results were very similar given the equal distribution of baseline characteristics, hence only the univariate $\mathrm{p}$ values are provided. In order to calculate sample size, the expected difference between the two groups and an acceptable type I and type II error must be known. Because no long term clinical trial had ever been performed comparing these two laser modalities, the expected difference was unknown. Hence a priori it was decided to enrol between $35-40$ patients in this phase I clinical trial.

All statistical analyses were performed with the software STATA (College Station, TX, USA). Significant $\mathrm{p}$ values were considered to 
Table 2 Change in IOP from baseline $(\mathrm{mm} \mathrm{Hg})$ at various time intervals

\begin{tabular}{|c|c|c|c|c|c|c|c|c|}
\hline $\begin{array}{l}\text { Eye } \\
\text { No }\end{array}$ & $\begin{array}{l}\text { Laser } \\
\text { received }\end{array}$ & Eye & $\begin{array}{l}\text { Baseline } \\
\text { IOP }\end{array}$ & At 1 hour & At 1 week & $\begin{array}{l}\text { At } 1 \\
\text { month }\end{array}$ & $\begin{array}{l}\text { At } 3 \\
\text { months }\end{array}$ & $\begin{array}{l}\text { At } 6 \\
\text { months }\end{array}$ \\
\hline 1 & SLT & $\mathrm{R}$ & 23 & +3 & +1 & -5 & -5 & -5 \\
\hline 2 & SLT & $\mathrm{R}$ & 22 & 0 & $-2^{\star}$ & $0^{\star}$ & -4 & -4 \\
\hline 3 & SLT & $\mathrm{L}$ & 22 & -2 & -1 & -2 & -4 & -5 \\
\hline 4 & SLT & $\mathrm{R}$ & 22 & -1 & -3 & -2 & -10 & -10 \\
\hline 5 & ALT & $\mathrm{L}$ & 24 & -5 & -5 & -1 & -5 & -4 \\
\hline 6 & ALT & $\mathrm{R}$ & 21 & -8 & -1 & -7 & -4 & -2 \\
\hline 7 & SLT & $\mathrm{R}$ & 26 & -2 & - & - & +4 & - \\
\hline 8 & ALT & $\mathrm{R}$ & 22 & -4 & -4 & -1 & - & -3 \\
\hline 9 & ALT & $\mathrm{L}$ & 22 & 0 & -2 & $+6 \dagger$ & -2 & -2 \\
\hline 10 & SLT & $\mathrm{L}$ & 26 & -4 & -5 & $-3^{\star}$ & +2 & 0 \\
\hline 11 & SLT & $\mathrm{L}$ & 26 & 0 & - & -5 & -6 & -6 \\
\hline 12 & SLT & $\mathrm{L}$ & 26 & -2 & +2 & $-2^{\star}$ & $-2^{\star} \dagger$ & +2 \\
\hline 13 & ALT & $\mathrm{L}$ & 23 & -8 & -6 & -5 & -6 & -4 \\
\hline 14 & ALT & $\mathrm{L}$ & 20 & -6 & -5 & -8 & -9 & -6 \\
\hline 15 & SLT & $\mathrm{R}$ & 25 & -9 & -9 & -10 & -9 & -9 \\
\hline 16 & ALT & $\mathrm{R}$ & 19 & -1 & -7 & $0 \ddagger$ & +1 & -2 \\
\hline 17 & ALT & $\mathrm{L}$ & 25 & +3 & -6 & -8 & $-5^{\star}$ & -11 \\
\hline 18 & ALT & $\mathrm{L}$ & 20 & -2 & -1 & -3 & - & -2 \\
\hline 19 & SLT & $\mathrm{L}$ & 23 & 0 & $-6^{\star}$ & $+1^{\star}$ & -4 & -3 \\
\hline 20 & SLT & $\mathrm{L}$ & 19 & -1 & -4 & -9 & -9 & -9 \\
\hline 21 & SLT & $\mathrm{R}$ & 17 & -5 & +1 & -2 & -4 & -5 \\
\hline 22 & ALT & $\mathrm{R}$ & 23 & -7 & -5 & -2 & -3 & -7 \\
\hline 23 & ALT & $\mathrm{R}$ & 20 & -3 & - & $0^{\star}$ & 0 & -2 \\
\hline 24 & SLT & $\mathrm{R}$ & 25 & +1 & -9 & $-5^{\star}$ & -9 & -10 \\
\hline 25 & SLT & $\mathrm{R}$ & 23 & 0 & +6 & -1 & 0 & -1 \\
\hline 26 & SLT & $\mathrm{R}$ & 18 & -6 & -2 & 0 & -2 & -4 \\
\hline 27 & ALT & $\mathrm{L}$ & 20 & -5 & -6 & -4 & -6 & -4 \\
\hline 28 & ALT & $\mathrm{R}$ & 18 & 0 & +1 & +1 & $+3^{\star}$ & -1 \\
\hline 29 & ALT & $\mathrm{L}$ & 28 & -10 & -13 & -13 & -10 & -10 \\
\hline 30 & SLT & $\mathrm{L}$ & 27 & +4 & $-9^{\star}$ & $+4 \S$ & -1 & -6 \\
\hline 31 & SLT & $\mathrm{R}$ & 20 & 0 & -3 & -1 & +2 & -2 \\
\hline 32 & ALT & $\mathrm{L}$ & 29 & -1 & -10 & -4 & $+1^{\star}$ & -12 \\
\hline 33 & ALT & $\mathrm{R}$ & 23 & -5 & $+1^{\star}$ & -5 & -3 & -5 \\
\hline 34 & ALT & $\mathrm{L}$ & 30 & -4 & 0 & $0^{\star}$ & $+4^{\star}$ & -2 \\
\hline 35 & ALT & $\mathrm{R}$ & 18 & +2 & -3 & - & -4 & -6 \\
\hline 36 & SLT & $\mathrm{R}$ & 20 & -2 & -2 & - & -4 & -4 \\
\hline
\end{tabular}

$\mathrm{ALT}=$ argon laser trabeculoplasty; SLT = selective laser trabeculoplasty; a positive number indicates an increase in pressure and a negative number, a decrease in pressure.

$-=$ no follow up data available.

$\star$ = Change in medication.

$\dagger=$ Repeat ALT.

$\ddagger=$ Excimer refractive surgery done at $1 \frac{1 / 2}{2}$ months

$\mathbb{S}=$ Filtering surgery done at $11 / 2$ months.

be less than or equal to 0.05 . All tests were performed two tailed.

The primary outcome variable was a change in IOP from baseline. Secondary outcomes were anterior chamber reaction and Snellen visual acuity. All patients who were randomised were analysed in an intent to treat analysis.

\section{Results}

In all, 36 eyes of 34 patients were included; 15 eyes had previously received ALT. The average follow up time for 1,3 , and 6 months visit was 34.2 (SD 7.8), 90.6 (10.3), 184.7 (17.0) days, respectively. At the start of the study there were 18 eyes in each group. All baseline characteristics including IOP were similarly distributed in the two groups. The baseline characteristics of

Table 3 Mean IOP (SD) ( $\mathrm{mm} \mathrm{Hg}$ ) at baseline and at different time intervals following SLT or $A L T$

\begin{tabular}{lllllll}
\hline & Baseline & 1 hour & 1 week & 1 month & 3 months & 6 months \\
\hline SLT & $22.8(3.0)$ & $21.3(4.9)$ & $19.5(4.2)$ & $20.1(4.6)$ & $19.3(6.0)$ & $17.8(4.8)$ \\
ALT & $22.5(3.6)$ & $18.9(4.2)$ & $18.4(4.1)$ & $19.5(4.7)$ & $19.6(5.6)$ & $17.7(3.3)$ \\
p Value & 0.80 & 0.13 & 0.43 & 0.74 & 0.88 & 0.97 \\
\hline
\end{tabular}

$\star$ By non-paired $t$ test.

Table 4 Mean drop in IOP ( $\mathrm{mm} \mathrm{Hg}$ ) at different time intervals following SLT or ALT

\begin{tabular}{llllll}
\hline & 1 hour & 1 week & 1 month & 3 months & 6 months \\
\hline SLT & $1.4(3.1)$ & $2.8(4.2)$ & $2.6(3.5)$ & $3.4(4.6)$ & $4.8(3.4)$ \\
ALT & $3.5(3.6)$ & $4.2(3.9)$ & $3.2(4.4)$ & $3.0(4.0)$ & $4.7(3.3)$ \\
p Value & 0.06 & 0.31 & 0.69 & 0.79 & 0.97
\end{tabular}

$\star$ By non-paired $t$ test.
Table 5 Final outcome at 6 months in patients with previous failed $A L T$

\begin{tabular}{llll}
\hline $\begin{array}{l}\text { Treatment } \\
\text { received }\end{array}$ & $\begin{array}{l}\text { No of } \\
\text { patients }\end{array}$ & $\begin{array}{l}\text { Mean IOP } \\
(\mathrm{mm} \mathrm{Hg})\end{array}$ & $\begin{array}{l}\text { Drop in IOP } \\
(\mathrm{mm} \text { Hg) }\end{array}$ \\
\hline SLT & 7 & $15.3(3.4)$ & $6.8(2.4)$ \\
ALT & 8 & $19.1(3.8)$ & $3.6(1.8)$ \\
p Value & - & 0.06 & 0.01 \\
\hline
\end{tabular}

${ }^{\star}$ By non-paired $t$ test.

these patients are summarised in Table 1. It was noticed that ALT caused blanching and occasional bubble formation around the laser spot while during SLT, there was nil to mild reaction of the trabecular meshwork at most exposed sites. Both treatments were free of bleeding. Patients did not complain of any pain during treatment with either laser.

Table 2 shows the individual data for each patient at all time periods. It shows the change in IOP along with any intervention or change in medication performed in individual patients. Although we tried to keep the patients on a constant regimen of medications during the study period, in 12 eyes (six eyes in each group) a change in medication occurred to control the IOP. The average number of medications at baseline and 6 months was 2.3 and 2.5 respectively in the SLT group, and 1.8 and 2.1 respectively in the ALT group. Table 3 shows the mean intraocular pressure at baseline and after laser trabeculoplasty at 1 hour, 1 week, 1, 3, and 6 months whereas Table 4 shows the mean reduction in IOP at these time intervals. IOP measurements obtained 1 hour after treatment were higher with SLT than with ALT, although the results were not statistically significant $(p=0.13)$. At 1 month there were 16 patients in the SLT and 17 patients in the ALT groups. Patient number 30 (Table 2) belonging to the SLT group had trabeculitis post-laser with uncontrolled high pressure. Trabeculectomy was done in his eye at the end of $1 \frac{1 / 2}{2}$ months. This patient had developed a similar reaction to ALT in the fellow eye 1 year earlier also necessitating filtering surgery. At 3 months, there were 18 patients in the SLT group and 16 patients in the ALT group. At 6 months, there were 17 patients in the SLT group and 18 patients in the ALT group. Figure 1 shows the trial profile summarising the participant flow, numbers, intervention, measurements, and completeness of the follow up. Table 5 shows the mean intraocular pressures at 6 months in eyes $(n=15)$ with a previous failed ALT. In this group, eyes treated with SLT had a significantly better final outcome in terms of drop in IOP compared with those treated with repeat ALT. When we eliminated the "previous ALT" subgroup from our analysis, the mean 6 month IOP was 19.6 (4.9) $\mathrm{mm} \mathrm{Hg}$ in the SLT group and 16.7 (2.62) $\mathrm{mm}$ in the ALT group. This difference was not statistically significant $(p=0.69)$.

A multivariate analyses was done at 6 months taking all baseline characteristics and the type of laser used into consideration and analysing their effect on the final intraocular pressures. It was found that the only predictor of final intraocular pressure at 6 months was the baseline intraocular pressure-that is, 


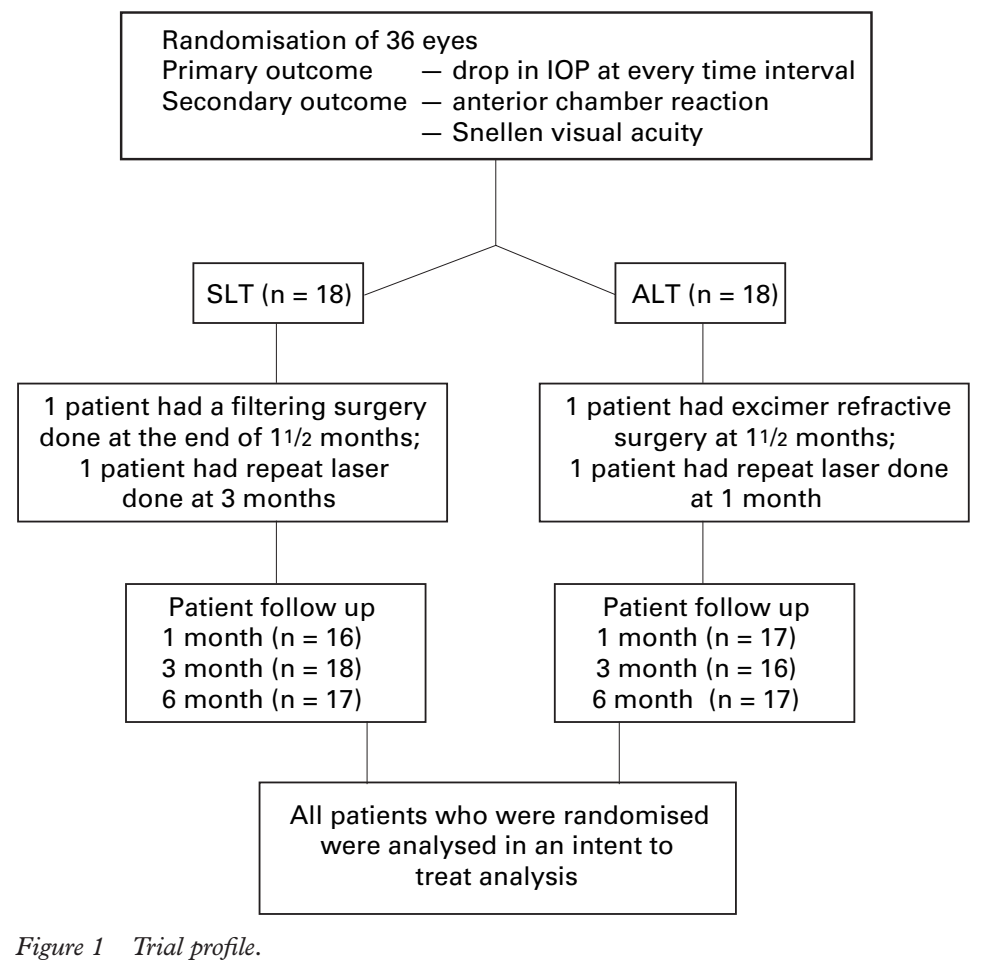

Table 6 Anterior chamber reaction 1 hour post-laser

\begin{tabular}{lll}
\hline & Mean flare & Mean cells \\
\hline SLT & $1.0(0.6)$ & $1.6(0.8)$ \\
ALT & $0.8(0.6)$ & $0.9(0.6)$ \\
p Value & 0.39 & 0.009 \\
\hline
\end{tabular}

$\star$ By non-paired $t$ test.

patients with lower baseline IOP had lower IOP at 6 months.

Secondary outcomes were anterior chamber reaction and Snellen visual acuity. Table 6 shows the anterior chamber reaction in terms of cells and flare 1 hour post-laser. There were significantly higher number of cells in the anterior chamber after SLT $v$ ALT $(\mathrm{p}<0.01)$. There was no change in visual acuity throughout the study in the two groups.

\section{Discussion}

In this study we compared the standard continuous wave argon laser and a $\mathrm{Q}$ switched frequency doubled (523 nm) Nd:YAG laser. Our results showed that over 6 months' duration there was no statistically significant difference in the intraocular pressures in the two groups. To the best of our knowledge, no prospective randomised clinical trial with 6 months' follow up comparing these two lasers has been reported previously in the literature. Tabak et $a l^{6}$ conducted a prospective randomised trial simultaneously treating one eye of a patient with SLT and the other with ALT. They found an equivalent decrease in IOP at 4 weeks (ALT $n=17$, SLT $n=22$ ) in both the groups. Longer follow up was not reported. Pirnazar et al ${ }^{7}$ conducted a retrospective study comparing ALT (27 eyes) with SLT (30 eyes) and found no difference in IOP drop at 1, 6, and 12 months post treatment.

ALT has been a standard therapeutic intervention in open angle glaucoma. ${ }^{1-4}$ The 5 year success rate with ALT is reported to be $50 \%$, with a decrease of $6 \%$ to $10 \%$ per year. ${ }^{4}$ The drawbacks of argon gas laser, however, include high cost, large power supply system, large size, low electrical to optical efficiency, and plasma tube degradation with time. ${ }^{10}$ As a possible alternative to this laser a number of other wavelengths are being tested. The laser used in this study is a Nd:YAG laser, which is a solid state laser. It has the advantages of less cost, smaller size, longer duration, and high electrical to optical efficiency. Although a number of previous studies have been done using Nd:YAG laser trabeculoplasty in animal models and in human glaucomatous eyes, ${ }^{11-16}$ these studies used Nd:YAG either in the continuous wave or free running mode with a wavelength of $1064 \mathrm{~nm}$. We used a Q switched, frequency doubled Nd:YAG (532 nm) which combines the advantage of solid state lasers with the emission of monochromatic green wavelength light. In this system, infrared radiation is filtered and only the visible component $(532 \mathrm{~nm})$ is used. This uses an effect similar to monochromatic argon green light $(514 \mathrm{~nm}){ }^{10}$ An additional advantage of $532 \mathrm{~nm}$ laser over $1064 \mathrm{~nm}$ laser is that optical absorption by melanin increases with the decrease in wavelength, thus lower threshold energy is required for a similar effect.

Frequency doubled Nd:YAG laser with pulse of short duration and low fluence (energy/area) has been found in tissue cultures, to selectively target pigmented TM cells while sparing adjacent cells and tissues from collateral thermal damage. It may thus have the advantage of better maintaining the architecture of the TM compared with ALT. ${ }^{8}$ The exact mechanism of action of this selective laser trabeculoplasty is not known. However, since minimal mechanical damage is thought to occur, a predominately cellular theory has been proposed to explain an improvement in outflow facility. According to Hollo, ${ }^{11}$ following ALT, the uveoscleral meshwork is severely destroyed in the area of the laser spots and the surrounding collagen fibres are heat damaged. A membrane is formed by migrating endothelial cells, which covers the meshwork between the laser spots and is responsible for the late pressure rise and treatment failure after ALT. This endothelial membrane and thermal damage was not seen after $532 \mathrm{~nm} \mathrm{Nd:YAG} \mathrm{laser}$ trabeculoplasty. ${ }^{11}$ Noecker et $a l^{17}$ studied the morphological changes after SLT and ALT in human postmortem eyes. They found that there was no coagulative damage to the human TM after SLT compared with ALT. This may offer a theoretical advantage for treatment with laser or topical medications if needed in the future.

SLT uses a pulse duration of 3 ns compared with ALT which has a pulse duration in the range of $1 \mathrm{~ms}$ or greater. According to Latina and Park, ${ }^{8}$ at pulse duration between $10 \mathrm{~ns}$ and $1 \mu$ s energy is deposited within the target (pigmented TM cells) more rapidly than it can diffuse away, hence minimising damage to the surrounding non-pigmented TM cells. Hence with pulse duration of 3 ns, SLT selectively 
confines the energy to the pigmented cells, whereas in ALT, heat gets dissipated from the pigmented cells to the surrounding tissues, damaging the non-pigmented cells within the irradiation zone. One interesting observation in our study was almost nil to mild visible reaction on the TM in response to the SLT impacts. In contrast, after ALT there was a bubble formation or blanching seen. This may be the result of deeper tissue penetration of the $\mathrm{Nd}$ :YAG laser energy in comparison with argon laser energy, which is deposited near the TM surface. ${ }^{8}$

We also found that the anterior chamber reaction 1 hour post-laser was significantly greater in the SLT group than in the ALT group. A possible explanation for this may be the large spot size used for SLT $400 \mu \mathrm{m} v 50$ $\mu \mathrm{m}$ in ALT. The large spot size in SLT is used to maintain a low fluence (energy/area) which is essential for the selectivity of this laser. ${ }^{8}$ Because of such a large spot size, the laser beam probably has an effect on the pigmented cells not only in the TM but also in the ciliary body and surrounding iris. This may be responsible for the increased anterior chamber reaction.

An intriguing finding in our study was that in patients with previous ALT there was a statistically greater drop in IOP after SLT than after repeat ALT. This could probably be explained on the basis that ALT may have a predominantly "mechanical" action while SLT may mainly have a "cellular" effect, thus adding an additional mechanism to further reduce the IOP.

In summary, SLT appears to be equivalent to ALT in lowering intraocular pressures in patients with open angle glaucoma. There is a slightly greater post-laser anterior chamber reaction at 1 hour after SLT. Interestingly, patients with previous failed ALT had a better outcome when treated with SLT $v$ ALT. These results are encouraging and suggest that SLT should be investigated further as an IOP lowering treatment in open angle glaucoma, espe- cially in patients with previously failed ALT. Nevertheless our results need to be verified with a phase III clinical trial.

This study was supported by Coherent Medical Group Palo Alto, CA 94303-0810.

The authors have no proprietary interest in the Selecta 7000 laser or in Coherent Medical.

1 The Glaucoma Laser Trial Research Group. The Glaucoma Laser Trial (GLT), II: Results of argon laser trabeculoplasty vs topical medicines. Ophthalmology 1990;97:1403-

2 Reiss GR, Wilensky JT, Higginbotham EJ. Laser trabeculoplasty. Surv Ophthalmol 1991;35:407-28.

3 Wise JB, Witter SL. Argon laser therapy for open angle glaucoma. Arch Ophthalmol 1979;97:319-22.

4 Weinreb RN, Tsai CS. Laser trabeculoplasty. In: Ritch R, Shields MB, Krupin T, eds. The glaucomas: glaucoma therapy. 2nd ed. Missouri: Mosby-Year Book, 1996;III: 1575-90.

5 Mermound A, Herbort CP, Schnyder CC, et al. Comparison of the effects of trabeculoplasty using the Nd:YAG laser and argon laser. Klin Monatsbl Augenheilkd 1992;200:4046.

6 Tabak S, de Waard PWT, Lemij HG, et al. Selective laser trabeculoplasty in glaucoma. Invest Ophthalmol Vis Sci 1998;39:S472.

7 Pirnazar JR, Kolker A, Wax M, et al. The efficacy of $532 \mathrm{~nm}$ laser trabeculoplasty. Invest Ophthalmol Vis Sci 1998;39:S5.

8 Latina MA, Park C. Selective targeting of trabecular meshwork cells: in vitro studies of pulsed and $\mathrm{cw}$ laser interactions. Exp Eye Res 1995;60:359-72.

9 Hogan MJ, Kimura SJ, Thygeson P. Signs and symtoms of uveitis. I: Anterior uveitis. Am f Ophthalmol 1959;47:155.

10 Bandello F, Brancato R, Lattanzio R, et al. Doublefrequency Nd:YAG laser vs argon green laser in the treatment of proliferative diabetic retinopathy: randomized study with long term follow-up. Lasers Surg Med 1996;19: 173-6.

11 Hollo G. Argon and low energy pulsed Nd:YAG laser trabeculoplasty. A prospective, comparative clinical and 31 .

12 Kwasniewska S, Fankhauser F, Larsen SE, et al. The efficacy of cw Nd:YAG laser trabeculoplasty. Ophthalmic Surg 1993;24:304-8.

13 Robin AL, Pollack IP. Q-switched neodymium-YAG laser angle surgery in open angle glaucoma. Arch Ophthalmol 1985;103:793-5.

14 van der Zypen E, Fankhauser F, England C, et al. Morphology of the trabecular meshwork within monkey (Macaca specie) eyes after irradiation with free-running Nd:YAG laser. Ophthalmology 1987;94:171-9.

15 Dueker DK, Norberg M, Johnson DH, et al. Stimulation of cell division by argon and Nd:YAG laser trabeculoplasty in cynomolgus monkeys. Invest Ophthalmol Vis Sci 1990;31: 115-24.

16 Del Priore LV, Robin AL, Pollack IP. Long term follow-up of Nd:YAG laser angle surgery for open angle glaucoma. of Nd:YAG laser angle surgery

17 Noecker RJ, Kramer TR, Latina M, et al. Comparison of acute morphologic changes after selective laser trabeculoplasty and argon laser trabeculoplasty by electron microscopic evaluation. Invest Ophthalmol Vis Sci 1998;39:S472. 